\title{
Maternal Vitamin D Deficiency and Fetal Growth
}

\author{
Christos loannou
}

\begin{abstract}
There is increasing incidence of vitamin D deficiency in pregnancy in developed countries. Dark skinned women who have migrated and live in higher latitudes are at greatest risk. Vitamin D supplementation is now recommended in several countries, yet its impact on fetal growth remains unclear. Observational studies suggest a possible correlation between maternal serum vitamin $D$ and birth weight. However, differences in birth weight can be confounded by soft-tissue growth and placental function. The effect on vitamin $D$ on bone mineral indices using dual energy $X$-ray absorptiometry is difficult to ascertain in the neonatal period and therefore remains unclear. Prenatal ultrasound is a safe and practical modality for assessing skeletal growth, yet very few studies have investigated fetal growth in the context of vitamin D status: one study has demonstrated no correlation with femur length, whereas two studies have shown positive correlations with femur length and femur volume respectively. The effect of vitamin $D$ supplementation on birth weight has been investigated in seven interventional studies. However, there is considerable methodological heterogeneity and high risk of bias among some of them. Meta-analysis of well conducted randomized controlled trials (RCTs) has not demonstrated a significant effect on birth weight. The effect of vitamin $D$ supplementation on ultrasound markers of fetal growth has not been reported to date. In summary, there is weak evidence that maternal vitamin D status may have a positive association with measures of fetal skeletal growth. However, if such an association exists, it is not clear whether it is causal or spurious. Randomized controlled trials of vitamin D supplementation are needed, where fetal ultrasound and neonatal bone mineral indices will be reported as primary outcome measures.
\end{abstract}

Keywords: 3D ultrasound, Biometry, Femur, Vitamin D.

How to cite this article: loannou C. Maternal Vitamin D Deficiency and Fetal Growth. Donald School J Ultrasound Obstet Gynecol 2015;9(3):223-229.

Source of support: Nil

Conflict of interest: None

\section{INTRODUCTION}

There has been an increased incidence of clinical and subclinical vitamin D deficiency in developed countries in recent years. ${ }^{1}$ Observational $^{2}$ and interventional

Consultant

Nuffield Department of Obstetrics and Gynecology, University of Oxford, UK

Corresponding Author: Christos loannou, Consultant, Nuffield Department of Obstetrics and Gynecology, University of Oxford United Kingdom, e-mail: chrisioannou@doctors.org.uk studies ${ }^{3}$ have suggested that such deficiency in pregnancy may lead to an increased risk of obstetric complications, for instance, pre-eclampsia, gestational diabetes and primary cesarean section. However, its impact on the developing fetus is much less clear. It is possible that lack of maternal vitamin D may contribute to suboptimal skeletal growth during intrauterine life, which in turn may predispose to a raised lifetime risk of osteoporosis, as a result of fetal programming. 4

The objectives of this review are (1) to summarize the epidemiology and physiological effects of vitamin D during pregnancy and (2) to investigate the effect of maternal deficiency and supplementation on the developing fetus.

\section{MAIN RESULTS}

\section{Physiology of Vitamin D}

Vitamin D3 (or cholecalciferol) is synthesized by human skin cells, through ultraviolet B (UVB)-induced photo conversion of 7 -dehydrocholesterol. ${ }^{5}$ It can also be obtained through a diet rich in animal and fish fat. Vitamin D2 (or ergocalciferol) is a similar compound of plant origin, which is at least three times less biologically active compared with D3, when given in supplement form. ${ }^{6}$

Whether endogenously synthesized or acquired through diet, vitamin $\mathrm{D}$ is then transformed into 25 $(\mathrm{OH}) \mathrm{D}$ by the addition of a hydroxyl group at the $25^{\prime}$ position. ${ }^{7}$ Although $25(\mathrm{OH}) \mathrm{D}$ is not biologically active, it represents the body's main store of vitamin D and it is also the main circulating form which is usually bound to a carrier, the vitamin D binding protein (DBP). 25-hyxroxyvitamin D can easily be measured in human serum, using widely available biologic assay kits and it is the molecule which is commonly referred to as 'vitamin $\mathrm{D}^{\prime}$ in everyday clinical practice.

The biologically active compound $1,25(\mathrm{OH})_{2} \mathrm{D}$ is generated by the addition of a second hydroxyl group at the 1 ' position, under the action of a renal hydroxylase. ${ }^{8}$ The production of $1,25(\mathrm{OH})_{2} \mathrm{D}$ is tightly coupled with its inactivation into $24,25(\mathrm{OH})_{2} \mathrm{D}$ by a different $24^{\prime}$ hydroxylase, forming a regulatory feedback loop. As a fat soluble vitamin, 1,25 $(\mathrm{OH})_{2} \mathrm{D}$ can enter the cell membrane through passive diffusion and then binds onto an intracellular vitamin D receptor (VDR). ${ }^{9}$ This vitamin-receptor complex acts as a gene transcription factor ${ }^{10}$ which promotes gene expression in several target 
tissues. The main ensuing effects include the increased provision of mineral, via intestinal absorption of calcium and phosphorus ${ }^{11}$ and calcium retention at the kidneys; ${ }^{11}$ a direct effect on the growth plate of long bones which promotes maturation and calcification; ${ }^{12}$ activation of osteoblasts-which increase the cellular bone component - and of osteoclasts which are necessary for bone remodelling, ${ }^{11}$ and finally non-skeletal effects, such as modulation of immune and inflammatory responses. 9 Those physiological actions stimulate the growth of long bones, through endochondral ossification at the level of the growth plate.

Defining an 'optimal' level of serum vitamin D has been the subject of considerable debate. In the literature deficiency and insufficiency have variously been defined using arbitrary cut-offs of $<12.5 \mathrm{nmol} / 1^{13},<15 \mathrm{nmol} / 1^{14},<25$ $\mathrm{nmol} / \mathrm{1}^{15},<27.5 \mathrm{nmol} / \mathrm{1}^{16},<40 \mathrm{nmol} / \mathrm{1}^{17}$ and $<50 \mathrm{nmol} / \mathrm{1}^{18}$. There is little doubt that rickets can manifest when serum levels fall below $25 \mathrm{nmol} / \mathrm{l}$; a syndrome characterized by growth failure and the typical appearance is costochondral beading, swelling of epiphyses and bowing of weight bearing bones, mainly of the legs. Rickets is now uncommon in the developed world with 2.9 new cases per $1,00,000$ children per year in Canada. ${ }^{19}$ Most authorities agree that $25 \mathrm{nmol} / 1$ is the threshold of such clinical deficiency. However, it is also well documented that an individual can maintain levels of $100 \mathrm{nmol} / 1$ or over, by means of adequate sunlight exposure alone. ${ }^{20}$ Levels between 25 and $100 \mathrm{nmol} / 1$ therefore represent a 'gray area', where the threshold level of subclinical deficiency or 'insufficiency' is difficult to establish. There are now increasing rates of such insufficiency, which is not severe enough to manifest as rickets, but may still result in suboptimal skeletal mineralization during childhood and puberty. ${ }^{11,21}$

An alternative strategy for defining insufficiency is indirectly through the metabolic effects of vitamin D supplementation. Individuals with low levels of vitamin $\mathrm{D}$ can have reduced serum calcium and raised parathyroid hormone (PTH) levels, known as secondary hyperparathyroidism. The therapeutic effect of vitamin $\mathrm{D}$ administration in those individuals can be assessed by measuring the reduction of PTH following supplementation; a study has shown that there is no added benefit from supplementation when the baseline vitamin D exceeds $50 \mathrm{nmol} / \mathrm{l}^{22}$ Levels between 25 and $50 \mathrm{nmol} / 1$ are therefore often regarded as insufficiency. To add further confusion to this debate, recent studies have suggested that the target range of serum vitamin $D$ for optimal health outcomes outside pregnancy should be 75 to $100 \mathrm{nmol} / \mathrm{l}^{23,24}$

There is huge geographical, cultural and interpersonal variation in natural sunlight exposure, dietary habits and clothing practices. As a result of this variation, the relative importance of dietary acquisition over endogenous vitamin D production is different for different populations. Reduced endogenous production can be caused by decreasing UVB exposure, as in the case of higher latitude, living indoors and clothing habits that limit skin exposure. Dietary acquisition of vitamin D then becomes an increasing necessity in order to maintain optimal bone health. Yet the dietary sources of vitamin D are fairly limited: oily fish, fortified margarines and some breakfast cereals, as well as smaller amounts in red meat and egg yolk. ${ }^{25}$ Populations at risk include dark skinned individuals ${ }^{26}$ who migrate and live at higher latitude, ${ }^{27}$ strict vegetarians; ${ }^{28}$ those who systematically avoid direct sunlight exposure; ${ }^{26}$ non-supplemented, exclusively breastfed infants; ${ }^{29}$ and pregnant women, ${ }^{11}$ especially those from any of the above risk groups.

\section{Vitamin D Insufficiency during Pregnancy}

The dual role of vitamin D during pregnancy is to maintain maternal skeletal health while at the same time facilitating the mobilization of mineral in order to support the developing fetus. Maternal serum levels of $25(\mathrm{OH}) \mathrm{D}$ generally remain stable during gestation in the absence of supplementation. ${ }^{1,30}$ In contrast, the concentration of the biologically active form $1,25(\mathrm{OH})_{2} \mathrm{D}$ in the mother doubles between the first and third trimesters. ${ }^{30}$ Increased availability of the active form drives increased maternal mineral absorption, which in turn supports the fetal calcium accrual, from approximately $50 \mathrm{mg} /$ day at around 20 weeks, to an average of $250 \mathrm{mg} /$ day during the third trimester. ${ }^{31}$

It is difficult to estimate the net effect of these changes on the maternal skeleton. Whilst a study of pre- and post-pregnancy bone mineral density measured by dual emission X-ray absorptiometry (DEXA) did not show any significant difference, ${ }^{30}$ a study of maternal bone density using quantitative calcaneal ultrasound (QUS) demonstrated a slight but significant bone mass reduction during the third trimester. ${ }^{32}$

Observational studies of serum vitamin D concentrations during gestation are indicative of high prevalence of subclinical vitamin D insufficiency in developed countries. Dark skinned women living at higher latitudes are at greater risk: $83 \%$ of pregnant Pakistani women living in Oslo have a vitamin D less than $30 \mathrm{nmol} / \mathrm{l}^{27}$ similarly $80 \%$ of veiled or dark-skinned pregnant women at their first antenatal appointment in Melbourne have concentrations less than $22.5 \mathrm{nmol} / 1 .{ }^{26}$ In the context of an interventional study of vitamin D supplementation in South Wales, 50\% of a cohort of non-caucasian pregnant women had levels $<20 \mathrm{nmol} / 1$ prior to supplementation. ${ }^{33}$ These reports are 
heavily selected as they contain samples of women at the highest risk of antenatal vitamin D deficiency.

Unselected population studies in the $\mathrm{US}^{1}, \mathrm{UK}^{34}$ and Australia ${ }^{35}$ demonstrate an overall prevalence of vitamin $\mathrm{D}$ deficiency in pregnancy $(<25 \mathrm{nmol} / \mathrm{l})$ between 7 and $18 \%$; vitamin D insufficiency and deficiency combined $(<50$ nmol/l) range from 33 to $49 \%$. Amongst non-supplemented pregnant women in the US, the rate of insufficiency reaches $66 \%$, compared with $49 \%$ in matched, nonpregnant controls. ${ }^{1}$ This demonstrates that pregnancy itself puts an added burden on the low vitamin D stores of a significant proportion of women in childbearing age.

It is evident that pregnant women may benefit from vitamin D supplementation, with the objective of optimizing their own skeletal health during pregnancy. Data from interventional ${ }^{36-38}$ as well as observational studies ${ }^{1}$ confirm that vitamin D supplementation during pregnancy increases maternal serum and neonatal cord vitamin D concentrations. Adequate supplementation for deficient women is likely to necessitate at least $25 \mu \mathrm{g}$ (1000 IU) daily and should start ideally in early, rather than late, gestation. ${ }^{33}$ The Canadian Pediatric Society now recommends routine supplementation for pregnant and lactating women with $50 \mu \mathrm{g}(2000 \mathrm{IU})$ of vitamin D daily. ${ }^{39}$ In 2008 the UK National Institute for Clinical Excellence endorsed supplementation of high-risk pregnant women with $10 \mu \mathrm{g}$ (400 IU) daily; ${ }^{25}$ this recommendation initially applied to women of South Asian, African, Caribbean or Middle Eastern family origin; those who have limited exposure to sunlight (housebound or covered when outdoors); those whose diet is low in oily fish, eggs, meat, vitamin D-fortified margarine or breakfast cereal; and those with a prepregnancy BMI of above $30 .{ }^{25}$ However, in 2012 the Chief Medical Officers in all four UK countries recommended that all pregnant women should receive $10 \mu \mathrm{g}$ (400 IU) daily.

\section{The Impact of Vitamin D on Fetal Growth}

Although vitamin D insufficiency is common during pregnancy, there are limited data about its effect on the fetus. Potential markers of fetal skeletal growth include neonatal indices, such as birth weight and neonatal bone mineral content (BMC) or bone mineral density (BMD); and prenatal ultrasonographic markers, such as femur length (FL) or more recently the femur volume (FV).

Birth weight has often been used as a surrogate marker of neonatal skeletal growth, given that there is a strong correlation between birth weight and BMC. ${ }^{40}$ There is a well-established seasonal variation of birth weight which could be explained by seasonal changes in sunlight exposure and maternal vitamin D levels. Studies from the northern and southern hemispheres, have demonstrated that population birth weights vary throughout the year, with a seasonal periodicity of approximately $30 \mathrm{gm}$. For instance, data from the Queensland perinatal register ${ }^{41}$ indicate that babies born in the winter months (June to October) are heavier than those born during the summer (January to May); similarly, babies born in Northern Ireland during the winter months (January to April) are heavier than those born during the summer (June to September) (Graph 1). ${ }^{42}$ It can be inferred that sunlight exposure in early pregnancy-rather than at the time of birth-replenishes the maternal vitamin D stores and subsequently stimulates fetal skeletal growth during the remainder of the pregnancy. A survey of 971 pregnant women in Australia ${ }^{35}$ demonstrated such a seasonal periodicity of their serum vitamin D levels; higher mean concentrations were noted in the sunny months of January to May. Babies born to vitamin D deficient mothers also had lower birth weight, with an adjusted mean difference of $151 \mathrm{gm}$.

The gold standard measure of neonatal skeletal growth is BMC and BMD, which can be assessed postnatally using dual energy X-ray absorptiometry (DEXA). ${ }^{43}$ However, this radiological technique involves a small amount of radiation exposure and has not been widely used in the literature to date. A cohort of 198 mothers and their children were followed-up postnatally at the age of 9, where a DEXA scan of the child was performed; it was demonstrated that maternal vitamin D insufficiency during pregnancy was associated with reduced BMC in childhood. ${ }^{34}$ It is not clear whether this difference could be attributed to altered growth as a result of intrauterine lack of vitamin D; or whether it was the consequence of postnatal nutritional deficiencies.

Femur length (FL) is the most widely used ultrasonographic marker of fetal bone growth, but no correlation between FL and maternal vitamin D level was found on a cohort of 424 women from Southampton, UK. ${ }^{44}$ However

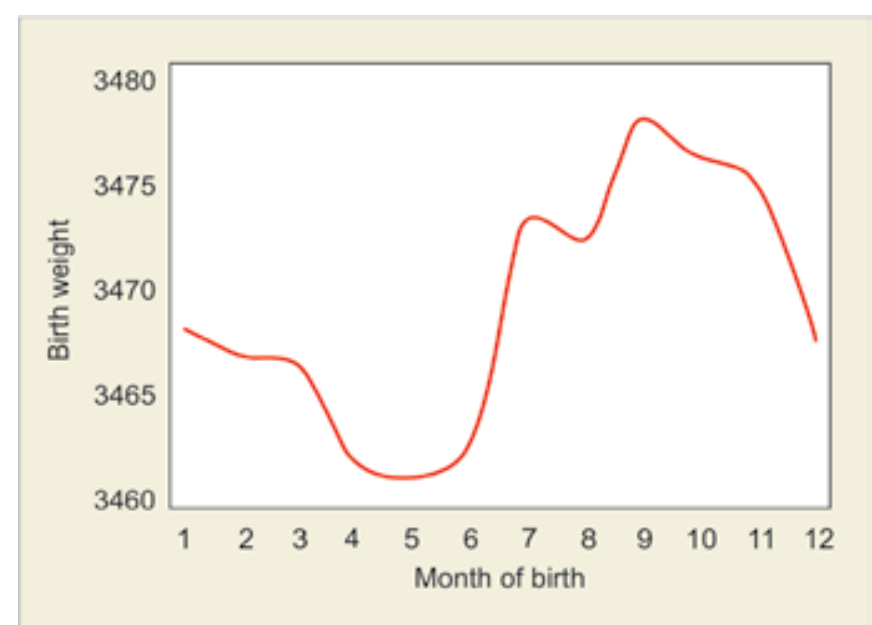

Graph 1: Yearly variation of birth weights according to the month of birth in Queensland, Australia; a peak is noted during the winter months June to December 
a positive correlation was demonstrated more recently in 171 pregnant adolescents from the $\mathrm{US}^{45}$ where higher maternal vitamin D levels were associated with longer fetal femurs.

Femur volume (FV) measurement can be performed using multiplanar tracing on 3D ultrasound. ${ }^{46}$ However, this technique has been shown to have poor interobserver agreement. ${ }^{47}$ A simple alternative method has been proposed and validated, ${ }^{48}$ which consists of three linear measures: the FL obtained from the standard 2D femoral plane (a plane of the 3D volume), the proximal metaphysis diameter (PMD) and mid-shaft diameter (MSD) obtained from the reconstructed $C$ plane and a volume equation. Using this method, a positive correlation was demonstrated between maternal vitamin D and FV; this correlation was mediated primarily through a significant positive effect on the PMD, but not the FL. This finding suggests that a possible fetal anabolic effect of vitamin D may be more evident in long bone girth that length.

\section{Interventional Studies: The Fetal Effect of Vitamin D Supplementation}

Animal experimental data support the hypothesis that vitamin D supplementation may improve fetal skeletal growth: administration of vitamin $\mathrm{D}$ to female pregnant rats was shown to increase the dry tibial weight, tibial ash weight and the whole body weight of the 28-day old offspring. 49

However, the evidence in humans is less clear. There is no evidence at present to suggest that vitamin D supplementation has any measurable impact of fetal ultrasound indices.

A single, non-randomized, cohort study assessed the neonatal BMC between supplemented and nonsupplemented pregnant women; an unvalidated method of radioisotope absorptiometry of the baby's forearm was used, but this did not demonstrate any difference between the study groups. ${ }^{50}$

The only existing evidence regarding the fetal effect of supplementation in pregnancy is using birth weight as outcome measure: we have identified 7 interventional studies $^{3,36-38,50-52}$ and one Cochrane systematic review. ${ }^{53}$ The latter has concluded that there is no significant effect of vitamin D supplementation on birth weight. Considerable methodological heterogeneity, conflicting results and a high risk of bias among some of the primary studies are making their interpretation difficult.

One of the primary studies reported no significant difference in birth weight but did not provide the birth weight data. ${ }^{37}$ A meta-analysis of birth weight data of all remaining six studies would indicate a significant increase of birth weight in the group of vitamin D supplemented women, with a mean difference of $138 \mathrm{gm}$ (Table 1). However, only three of the included studies are well-described randomized controlled trials (RCTs) $3,36,38$ whereas the other three are cohort or interventional studies ${ }^{50-52}$ with high risk of bias. Separate analysis of those three RCTs (Table 2) does not show any significant difference in birth weights between babies of supplemented mothers and those receiving placebo: one study found a non-significant trend for reduced birth weight in the supplementation group ${ }^{38}$ and two studies showed a trend for increased birth weight. 3,36 In one study there was a significant increase of infant weight at 1 year of age in children from supplemented pregnancies at their postnatal follow-up. ${ }^{54}$ There was also a significant reduction of the anterior fontanelle surface area measured clinically at birth, ${ }^{36}$ suggesting that babies after supplementation had better ossified fontanelles. This is an interesting finding since there is

Table 1: Meta-analysis of trials of vitamin D supplementation; all studies included

\begin{tabular}{|c|c|c|c|c|c|c|c|c|c|c|c|}
\hline \multirow{2}{*}{$\begin{array}{l}\text { Study or } \\
\text { subgroup }\end{array}$} & \multicolumn{3}{|c|}{$\begin{array}{l}\text { Vitamin D } \\
\text { supplement }\end{array}$} & \multicolumn{3}{|c|}{$\begin{array}{c}\text { Placebo or } \\
\text { no supplement }\end{array}$} & \multirow[b]{2}{*}{ Weight } & \multirow{2}{*}{$\begin{array}{l}\text { Mean difference } \\
\text { IV, fixed, } 95 \% \mathrm{Cl}\end{array}$} & \multirow[b]{2}{*}{ Years } & \multirow{2}{*}{\multicolumn{2}{|c|}{$\begin{array}{l}\text { Mean difference } \\
\text { IV, Fixed, } 95 \% \mathrm{Cl}\end{array}$}} \\
\hline & Mean & $S D$ & Total & Mean & $S D$ & Total & & & & & \\
\hline $\begin{array}{l}\text { Brooke } \\
(1000 \mathrm{IU})\end{array}$ & 3,157 & 468 & 59 & 3,034 & 523 & 67 & $13.2 \%$ & $\begin{array}{l}123.00 \\
(-50.04,296.04]\end{array}$ & 1980 & & \\
\hline $\begin{array}{l}\text { Marya } \\
(1200 \mathrm{IU})\end{array}$ & 2,890 & 320 & 25 & 2,730 & 360 & 75 & $17.6 \%$ & $\begin{array}{l}160.00 \\
{[10.43,309.57]}\end{array}$ & 1981 & & \\
\hline $\begin{array}{l}\text { Congdon } \\
\text { (1000 IU) }\end{array}$ & 3,173 & 471 & 19 & 3,056 & 396 & 45 & $6.8 \%$ & $\begin{array}{l}117.00 \\
{[-124.33,358.33]}\end{array}$ & 1983 & & \\
\hline $\begin{array}{l}\text { Delvin } \\
\text { (1000 IU) }\end{array}$ & 0 & 0 & 0 & 0 & 0 & 0 & & Not estimable & 1986 & & \\
\hline $\begin{array}{l}\text { Mallet } \\
\text { (1000 IU) }\end{array}$ & 3,370 & 367 & 21 & 3,460 & 377 & 29 & $9.1 \%$ & $\begin{array}{l}-90.00 \\
{[-298.48,118.48]}\end{array}$ & 1986 & $\begin{array}{c}-200-100 \\
\text { lacebo or no supplement }\end{array}$ & $\begin{array}{lll}1 & 1 & 1 \\
0 & 100 & 200 \\
\text { Vitamin D supplement }\end{array}$ \\
\hline $\begin{array}{l}\text { Marya } \\
(600,000 \mathrm{IU})\end{array}$ & 2,990 & 360 & 100 & 2,800 & 370 & 100 & $38.5 \%$ & $\begin{array}{l}190.00 \\
{[88.82,291.18]}\end{array}$ & 1988 & & \\
\hline $\begin{array}{l}\text { Hollis } \\
\text { (2000 IU) }\end{array}$ & 3,360 & 585 & 122 & 3,222 & 675 & 111 & $14.9 \%$ & $\begin{array}{l}138.00 \\
{[-24.92,300.92]}\end{array}$ & 2011 & & \\
\hline $\begin{array}{l}\text { Total } \\
(95 \% \mathrm{Cl})\end{array}$ & & & 346 & & & 427 & $100.0 \%$ & $\begin{array}{l}137.82 \\
{[75.03,200.62]}\end{array}$ & & & \\
\hline
\end{tabular}


Maternal Vitamin D Deficiency and Fetal Growth

Table 2: Meta-analysis of trials of vitamin D supplementation; only studies at low risk of bias included

\begin{tabular}{|c|c|c|c|c|c|c|c|c|c|c|}
\hline \multirow{2}{*}{$\begin{array}{l}\text { Study or } \\
\text { subgroup }\end{array}$} & \multicolumn{3}{|c|}{$\begin{array}{l}\text { Vitamin D } \\
\text { supplement }\end{array}$} & \multicolumn{3}{|c|}{$\begin{array}{c}\text { Placebo or } \\
\text { no supplement }\end{array}$} & \multirow[b]{2}{*}{ Weight } & \multirow{2}{*}{$\begin{array}{l}\text { Mean } \\
\text { difference } \\
I V, \text { fixed, } 95 \% \mathrm{Cl}\end{array}$} & \multirow[b]{2}{*}{ Years } & \multirow{2}{*}{$\begin{array}{l}\text { Mean difference } \\
\mathrm{IV} \text {, fixed, } 95 \% \mathrm{Cl}\end{array}$} \\
\hline & Mean & $S D$ & Total & Mean & $S D$ & Total & & & & \\
\hline $\begin{array}{l}\text { Brooke } \\
(1000 \mathrm{IU})\end{array}$ & 3,157 & 468 & 59 & 3,034 & 523 & 67 & $35.5 \%$ & $\begin{array}{l}123.00 \\
(-50.04,296.04]\end{array}$ & 1980 & + \\
\hline $\begin{array}{l}\text { Marya } \\
(1200 \mathrm{IU})\end{array}$ & 2,890 & 320 & 25 & 2,730 & 360 & 75 & $0.0 \%$ & $\begin{array}{l}160.00 \\
{[10.43,309.57]}\end{array}$ & 1981 & \\
\hline $\begin{array}{l}\text { Congdon } \\
\text { (1000 IU) }\end{array}$ & 3,173 & 471 & 19 & 3,056 & 396 & 45 & $0.0 \%$ & $\begin{array}{l}117.00 \\
{[-124.33,358.33]}\end{array}$ & 1983 & \\
\hline $\begin{array}{l}\text { Delvin } \\
(1000 \mathrm{IU})\end{array}$ & 0 & 0 & 0 & 0 & 0 & 0 & & Not estimable & 1986 & 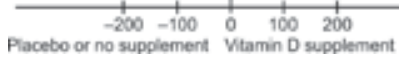 \\
\hline $\begin{array}{l}\text { Mallet } \\
(1000 \mathrm{IU})\end{array}$ & 3,370 & 367 & 21 & 3,460 & 377 & 29 & $24.5 \%$ & $\begin{array}{l}-90.00 \\
{[-298.48,118.48]}\end{array}$ & 1986 & \\
\hline $\begin{array}{l}\text { Marya } \\
(600,000 I U)\end{array}$ & 2,990 & 360 & 100 & 2,800 & 370 & 100 & $0.0 \%$ & $\begin{array}{l}190.00 \\
{[88.82,291.18]}\end{array}$ & 1988 & \\
\hline $\begin{array}{l}\text { Hollis } \\
(2000 \mathrm{IU})\end{array}$ & 3,360 & 585 & 122 & 3,222 & 675 & 111 & $40.0 \%$ & $\begin{array}{l}138.00 \\
{[-24.92,300.92]}\end{array}$ & 2011 & \\
\hline $\begin{array}{l}\text { Total } \\
(95 \% \mathrm{Cl})\end{array}$ & & & 202 & & & 207 & $100.0 \%$ & $\begin{array}{l}76.92 \\
{[-26.18,180.02]}\end{array}$ & & \\
\hline
\end{tabular}

Heterogeneity: $\mathrm{Chi}^{\mathrm{z}}=3.27, \mathrm{df}=2(p=0.19) ; \mathrm{I}^{\mathrm{z}}=39 \%$; Test for overall effect: $\mathrm{Z}=1.46(p=0.14)$

no direct physiological evidence to suggest that vitamin $\mathrm{D}$ plays any role in endomembranous bone homeostasis; however it is also known that aggressive treatment with vitamin D in X-linked hypophosphatemic rickets can cause premature suture obliteration. ${ }^{55}$ It is possible that vitamin D may exert an effect on fontanelle size indirectly as a result of increased mineral provision.

\section{DISCUSSION}

This review has demonstrated that, according to observational studies, ${ }^{35,45,48}$ a positive correlation may exist between maternal vitamin $\mathrm{D}$ and fetal skeletal growth. Nevertheless, interventional studies of vitamin D supplementation in pregnancy $3,36-38,50-52$ have not yet conclusively demonstrated any such effect on fetal indices.

One of the difficulties is how the effects of maternal vitamin D status on fetal development may be measured in order to be identified. A postnatal outcome measure, such as birth weight is easy to obtain, but it is a crude measure and can be confounded by the effect of softtissue growth and placental function. Conversely, specific skeletal markers, such as BMC or BMD should represent the gold standard method of assessing bone size and mineralization in the neonate. However, DEXA scans in the neonatal period are technically challenging; the earliest these could be performed is several days or weeks after the birth and therefore their results can be confounded by postnatal weight gain and nutrition; excessive movement of the newborn may also introduce considerable measurement error.

Ultrasound measures represent a suitable alternative, free of radiation exposure and acceptable to pregnant women. A correlation between vitamin $\mathrm{D}$ and $\mathrm{FL}^{45}$ or FV ${ }^{48}$ has been demonstrated in observational studies; however it is always difficult to establish the causal pathway in such observational associations. Furthermore when attributing increased bone length or bone volume to the action of maternal vitamin $\mathrm{D}$, an underlying assumption is made that such an increase is beneficial. However it is possible that bigger size does not always correspond to improved mineralization. In other words, one may speculate that if skeletal size increases in the absence of sufficient mineralization, then bone 'quality' may be inferior. Finally, it should be highlighted that the effect of vitamin D on FL or FV - whether real or spurious - is likely to be clinically small. Nevertheless, ultrasound measures, such as FL and FV are simple, non-invasive biometric indices; they do not carry radiation risk; and they could be used as outcome measures in interventional trials of vitamin D supplementation aimed at optimizing skeletal health in pregnancy. The paucity of ultrasound data in existing vitamin $\mathrm{D}$ trials is the unfortunate reflection of the fact that almost all of these were published in the early 1980s, before FL became an established tool for everyday fetal biometry. As the argument strengthens for vitamin D supplementation, more randomized trials are needed in order to answer the question regarding its effect on the developing fetus.

\section{REFERENCES}

1. Ginde AA, Sullivan AF, Mansbach JM, Camargo CA Jr. Vitamin D insufficiency in pregnant and nonpregnant women of childbearing age in the United States. Am J Obstet Gynecol 2010;202(5):436.e1-e8.

2. Hollis BW, Wagner CL. Vitamin D and pregnancy: skeletal effects, nonskeletal effects and birth outcomes. Calcif Tissue Int 2013;92(2):128-139. 
3. Hollis BW, Johnson D, Hulsey TC, Ebeling M, Wagner CL. Vitamin D supplementation during pregnancy: double-blind, randomized clinical trial of safety and effectiveness. J Bone Miner Res 2011;26(10):2341-2357.

4. Javaid MK, Cooper C. Prenatal and childhood influences on osteoporosis. Best Pract Res Clin Endocrinol Metab 2002; 16(2):349-367.

5. Norman AW. Sunlight, season, skin pigmentation, vitamin D, and 25-hydroxyvitamin D: integral components of the vitamin D endocrine system. Am J Clin Nutr 1998;67(6): 1108-1110.

6. Armas LA, Hollis BW, Heaney RP. Vitamin D2 is much less effective than vitamin D3 in humans. J Clin Endocrinol Metab 2004;89(11):5387-5391.

7. Ponchon G, Kennan AL, DeLuca HF. 'Activation' of vitamin D by the liver. J Clin Invest 1969;48(11):2032-2037.

8. Armbrecht HJ, Hodam TL, Boltz MA. Hormonal regulation of 25-hydroxyvitamin D3-1alpha-hydroxylase and 24-hydroxylase gene transcription in opossum kidney cells. Arch Biochem Biophys 2003;409(2):298-304.

9. Lips P. Vitamin D physiology. Prog Biophys Mol Biol 2006;92(1):4-8.

10. Jimenez-Lara AM, Aranda A. Interaction of vitamin D and retinoid receptors on regulation of gene expression. Horm Res 2000;54(5-6):301-305.

11. Kimball S, Fuleihan Gel-H, Vieth R. Vitamin D: a growing perspective. Crit Rev Clin Lab Sci 2008;45(4):339-414.

12. Stevens DA, Williams GR. Hormone regulation of chondrocyte differentiation and endochondral bone formation. Mol Cell Endocrinol 1999;151(1-2):195-204.

13. Ala-Houhala M, Parviainen MT, Pyykko K, Visakorpi JK. Serum 25-hydroxyvitamin D levels in finnish children aged 2 to 17 years. Acta Paediatr Scand 1984;73(2):232-236.

14. Guillemant J, Cabrol S, Allemandou A, Peres G, GuillemantS. Vitamin D-dependent seasonal variation of PTH in growing male adolescents. Bone 1995;17(6):513-516.

15. Andersen R, Molgaard C, Skovgaard LT, Brot C, Cashman KD, Chabros E, Charzewska J, Flynn A, Jakobsen J, Kärkkäinen M, et al. Teenage girls and elderly women living in northern Europe have low winter vitamin D status. Eur J Clin Nutr 2005;59(4):533-541.

16. Harkness LS, Cromer BA. Vitamin D deficiency in adolescent females. J Adolesc Health 2005;37(1):75.

17. Outila TA, Karkkainen MU, Lamberg-Allardt CJ. Vitamin D status affects serum parathyroid hormone concentrations during winter in female adolescents: associations with forearm bone mineral density. Am J Clin Nutr 2001;74(2): 206-210.

18. Hill TR, Cotter AA, Mitchell S, Boreham CA, Dubitzky W, Murray L, Strain JJ, Flynn A, Robson PJ, Wallace JM, et al. Vitamin D status and its determinants in adolescents from the Northern Ireland Young Hearts 2000 cohort. Br J Nutr 2008;99(5):1061-1067.

19. Ward LM, Gaboury I, Ladhani M, Zlotkin S. Vitamin D-deficiency rickets among children in Canada. CMAJ 2007;177(2):161-166.

20. Stein EM, Laing EM, Hall DB, Hausman DB, Kimlin MG, Johnson MA, Modlesky CM, Wilson AR, Lewis RD. Serum 25-hydroxyvitamin $\mathrm{D}$ concentrations in girls aged 4 to $8 \mathrm{y}$ living in the southeastern United States. Am J Clin Nutr 2006; 83(1):75-81.
21. Tylavsky FA, Ryder KA, Lyytikainen A, Cheng S. Vitamin D, parathyroid hormone, and bone mass in adolescents. J Nutr 2005;135(11):S2735-S2738.

22. Malabanan A, Veronikis IE, Holick MF. Redefining vitamin D insufficiency. Lancet 1998;351(9105):805-806.

23. Bischoff-Ferrari HA, Giovannucci E, Willett WC, Dietrich $T$, Dawson-Hughes B. Estimation of optimal serum concentrations of 25-hydroxyvitamin D for multiple health outcomes. Am J Clin Nutr 2006;84(1):18-28.

24. Holick MF, Binkley NC, Bischoff-Ferrari HA, Gordon CM, Hanley DA, Heaney RP, Murad MH, Weaver CM, Endocrine Society. Evaluation, treatment, and prevention of vitamin $\mathrm{D}$ deficiency: an endocrine society clinical practice guideline. J Clin Endocrinol Metab 2011;96(7):1911-1930.

25. National Institute for Health and Care Excellence. Antenatal care: routine care for the healthy pregnant woman (NICE clinical guideline 62) [Internet]. National Collaborating Centre for Women's and Children's Health, 2008. Available from: https://www.nice.org.uk/guidance/cg62.

26. Grover SR, Morley R. Vitamin D deficiency in veiled or darkskinned pregnant women. Med J Aust 2001;175(5):251-252.

27. Henriksen C, Brunvand L, Stoltenberg C, Trygg K, Haug E, Pedersen JI. Diet and vitamin D status among pregnant Pakistani women in Oslo. Eur J Clin Nutr 1995;49(3):211-218.

28. Finch PJ, Ang L, Colston KW, Nisbet J, Maxwell JD. Blunted seasonal variation in serum 25-hydroxy vitamin $\mathrm{D}$ and increased risk of osteomalacia in vegetarian London Asians. Eur J Clin Nutr 1992;46(7):509-515.

29. Munns C, Zacharin MR, Rodda CP, Batch JA, Morley R, Cranswick NE, Craig ME, Cutfield WS, Hofman PL, Taylor BJ, et al. Prevention and treatment of infant and childhood vitamin D deficiency in Australia and New Zealand: a consensus statement. Med J Aust 2006;185(5):268-272.

30. Ritchie LD, Fung EB, Halloran BP, Turnlund JR, Van Loan MD, Cann CE, King JC. A longitudinal study of calcium homeostasis during human pregnancy and lactation and after resumption of menses. Am J Clin Nutr 1998;67(4):693-701.

31. Prentice A. Calcium in pregnancy and lactation. Annu Rev Nutr 2000;20:249-272.

32. Gambacciani M, Spinetti A, Gallo R, Cappagli B, Teti GC, Facchini V. Ultrasonographic bone characteristics during normal pregnancy: longitudinal and cross-sectional evaluation. Am J Obstet Gynecol 1995;173(3):890-893.

33. Datta S, Alfaham M, Davies DP, Dunstan F, WoodheadS, Evans J, Richards B. Vitamin D deficiency in pregnant women from a non-European ethnic minority population-an interventional study. BJOG 2002;109(8):905-908.

34. Javaid MK, Crozier SR, Harvey NC, Gale CR, Dennison EM, Boucher BJ, Arden NK, Godfrey KM, Cooper C, Princess Anne Hospital Study Group. Maternal vitamin D status during pregnancy and childhood bone mass at age 9 years: a longitudinal study. Lancet 2006;367(9504):36-43.

35. Bowyer L, Catling-Paull C, Diamond T, Homer C, Davis G, CraigME. Vitamin D, PTH and calcium levels in pregnant women and their neonates. Clin Endocrinol (Oxf) 2009;70(3):372-377.

36. Brooke OG, Brown IR, Bone CD, Carter ND, Cleeve HJ, Maxwell JD, Robinson VP, Winder SM Vitamin D supplements in pregnant Asian women: effects on calcium status and fetal growth. Br Med J 1980;280(6216):751-754.

37. Delvin EE, Salle BL, Glorieux FH, Adeleine P, David LS. Vitamin D supplementation during pregnancy: effect on neonatal calcium homeostasis. J Pediatr 1986;109(2):328-334. 
38. Mallet E, Gugi B, Brunelle P, Hénocq A, Basuyau JP, Lemeur H. Vitamin D supplementation in pregnancy: a controlled trial of two methods. Obstet Gynecol 1986;68(3):300-304.

39. Vitamin D supplementation: recommendations for Canadian mothers and infants. Paediatr Child Health 2007; 12: 583-598.

40. Godfrey K, Walker-Bone K, Robinson S, Taylor P, Shore S, Wheeler T, Cooper C. Neonatal bone mass: influence of parental birthweight, maternal smoking, body composition, and activity during pregnancy. J Bone Miner Res 2001;16(9):1694-1703.

41. McGrath JJ, Keeping D, Saha S, Chant DC, Lieberman DE, O'Callaghan MJ. Seasonal fluctuations in birth weight and neonatal limb length; does prenatal vitamin D influence neonatal size and shape? Early Hum Dev 2005;81(7):609-618.

42. Murray LJ, O'Reilly DP, Betts N, Patterson CC, Davey Smith G, Evans AE. Season and outdoor ambient temperature: effects on birth weight. Obstet Gynecol 2000;96(5):689-695.

43. Dror DK, King JC, Fung EB, Loan MDV, Gertz ER, Allen LH. Evidence of associations between feto-maternal vitamin D status, cord parathyroid hormone and bone-specific alkaline phosphatase, and newborn whole body bone mineral content. Nutrients 2012;4(2):68-77.

44. Mahon P, Harvey N, Crozier S, Inskip H, Robinson S, Arden N, Swaminathan R, Cooper C, Godfrey K, SWS Study Group. Low maternal vitamin $\mathrm{D}$ status and fetal bone development: cohort study. J Bone Miner Res 2010;25(1):14-19.

45. Young BE, McNanley TJ, Cooper EM, McIntyre AW, Witter F, Harris ZL, O'Brien KO. Maternal vitamin D status and calcium intake interact to affect fetal skeletal growth in utero in pregnant adolescents. Am J Clin Nutr 2012;95(5):1103-1112.

46. Chang $\mathrm{CH}$, Tsai PY, Yu CH, Ko HC, Chang FM. Prenatal detection of fetal growth restriction by fetal femur volume: efficacy assessment using three-dimensional ultrasound. Ultrasound Med Biol 2007;33(3):335-341.

47. Ioannou C, Sarris I, Salomon LJ, Papageorghiou AT. A review of fetal volumetry: the need for standardization and definitions in measurement methodology. Ultrasound Obstet Gynecol 2011;38(6):613-619.

48. Ioannou C, Javaid MK, Mahon P, Yaqub MK, Harvey NC, Godfrey KM, Noble JA, Cooper C, Papageorghiou AT. The effect of maternal vitamin D concentration on fetal bone. J Clin Endocrinol Metab 2012;97(11):E2070-E2077.

49. Marya RK, Saini AS, Jaswal TS. Effect of vitamin D supplementation during pregnancy on the neonatal skeletal growth in the rat. Ann Nutr Metab 1991;35(4):208-212.

50. Congdon P, Horsman A, Kirby PA, Dibble J, Bashir T. Mineral content of the forearms of babies born to Asian and white mothers. Br Med J (Clin Res Ed) 1983;286(6373):1233-1235.

51. Marya RK, Rathee S, Lata V, Mudgil S. Effects of vitamin D supplementation in pregnancy. Gynecol Obstet Invest 1981; 12(3):155-161.

52. Marya RK, Rathee S, Dua V, Sanwan K. Effect of vitamin D supplementation during pregnancy on foetal growth. Indian J Med Res 1988;88:488-492.

53. De-Regil LM, Palacios C, Ansary A, Kulier R, Peña-Rosas JP. Vitamin D supplementation for women during pregnancy. Cochrane Database Syst Rev 2012;2:CD008873.

54. Brooke OG, Butters F, Wood C. Intrauterine vitamin D nutrition and postnatal growth in Asian infants. Br Med J (Clin Res Ed) 1981;283(6298):1024.

55. Carlsen NL, Krasilnikoff PA, Eiken M. Premature cranial synostosis in X-linked hypophosphatemic rickets: possible precipitation by 1-alpha-OH-cholecalciferol intoxication. Acta Paediatrica Scandinavica 1984;73(1):149-154. 